\title{
Outcome of platinum-based chemotherapy for non-small-cell lung cancer patients with pleural dissemination detected during surgery
}

\author{
MADOKA KIMURA $^{1}$, HARUYASU MURAKAMI ${ }^{1}$, TATEAKI NAITO ${ }^{1}$, HIROTSUGU KENMOTSU ${ }^{1}$, \\ TETSUHIKO TAIRA ${ }^{1}$, HIROAKI AKAMATSU ${ }^{1}$, AKIRA ONO ${ }^{1}$, HISAO IMAI ${ }^{1}$, TOSHIAKI TAKAHASHI ${ }^{1}$, \\ MASAHIRO ENDO $^{2}$, TAKASHI NAKAJIMA ${ }^{3}$, YASUHISA OHDE ${ }^{4}$ and NOBUYUKI YAMAMOTO ${ }^{1}$ \\ Divisions of ${ }^{1}$ Thoracic Oncology, ${ }^{2}$ Diagnostic Radiology, ${ }^{3}$ Diagnostic Pathology and ${ }^{4}$ Thoracic Surgery, \\ Shizuoka Cancer Center, Sunto-gun, Shizuoka 411-8777, Japan
}

Received February 20, 2013; Accepted June 25, 2013

DOI: $10.3892 / \mathrm{mco} .2013 .164$

\begin{abstract}
Pleural dissemination detected by computed tomography $(\mathrm{CT})$ is considered to be unfavorable for patients with non-small-cell lung cancer (NSCLC). However, the prognosis of NSCLC patients who are diagnosed with pleural dissemination at the time of surgery has yet to be adequately elucidated. To assess the outcomes of platinum-based chemotherapy in NSCLC patients in whom pleural dissemination was detected during exploratory thoracotomy with or without a videoscope, the clinical records of NSCLC patients who were admitted to Shizuoka Cancer Center between September, 2002 and April, 2009 were reviewed. A total of 19 patients were included in this study, 12 males and 7 females, with a median age of 65 years. All patients were diagnosed with adenocarcinoma and 6 were epidermal growth factor receptor (EGFR) gene mutation-positive. The median number of treatment cycles of first-line platinum-based chemotherapy was 4 (range, $1-6$ cycles) and the objective response rate was $21 \%$ [95\% confidence interval (CI): 8.5-43]. The median progression-free and overall survival were 10.4 (95\% CI: 6.3-18.4) and 50.5 months (95\% CI: 32.5-98.0), respectively. Of the 18 patients with reported disease progression, 9 (50\%) developed locoregional tumor progression. In conclusion, NSCLC patients in whom pleural dissemination is detected during surgery tend to have a favorable prognosis for survival. Systemic chemotherapy and additional local treatment may improve their clinical outcomes.
\end{abstract}

Correspondence to: Dr Haruyasu Murakami, Division of Thoracic Oncology, Shizuoka Cancer Center, 1007 Shimonagakubo Nagaizumi-cho, Sunto-gun, Shizuoka 411-8777, Japan

E-mail: ha.murakami@scchr.jp

Key words: non-small-cell lung cancer, pleural dissemination, surgery, unresectable, chemotherapy

\section{Introduction}

In early-stage non-small-cell lung cancer (NSCLC), surgical resection is the core of curative treatment. However, unexpected pleural dissemination is occasionally detected during surgery. According to TNM revisions (7th edition) and new stage groupings proposed by the International Association for the Study of Lung Cancer (IASLC), patients with pleural dissemination are classified as stage IV $(1,2)$. Therefore, when malignant pleuritis is identified during thoracotomy, resection of the primary tumor is considered to be a contraindication and the thorax is closed without performing resection (1-5). In the majority of cases, these patients are administered systemic chemotherapy. Previous studies on platinum-based chemotherapy in patients with advanced NSCLC reported that the median progression-free survival (PFS) and overall survival (OS) were 3.1-4.8 and 11.4-15.2 months, respectively (6-8). However, there is little available data on systemic chemotherapy and prognosis for NSCLC patients with pleural dissemination detected during surgery, compared to patients who are preoperatively diagnosed as stage IV by thorough examination. The aim of this study was to assess the outcome of platinum-based chemotherapy in NSCLC patients with pleural dissemination detected during surgery who did not undergo any form of resection.

\section{Patients and methods}

Study population. The subjects of this study were non-resected NSCLC patients with pleural dissemination detected during thoracotomy. Patient selection was performed based on the clinical records of NSCLC patients who underwent thoracotomy with or without videoscope at Shizuoka Cancer Center between September, 2002 and April, 2009. Ethics approval for this study was obtained by the Institutional Review Board. Written informed consent was obtained from the patients.

Of the 681 patients who underwent thoracotomy, pleural dissemination was identified in 31 patients during exploratory thoracotomy. Of these 31 patients who did not undergo any form of resection, 19 received platinum-doublet chemotherapy. The 
19 patients underwent preoperative workup, including chest X-ray, bronchoscopy, computed tomography (CT) scans of the chest and spirometry. A thorough search for distant metastases was also conducted, including magnetic resonance imaging of the brain in 17 patients (89\%) and positron emission tomography scans in 18 patients $(95 \%)$, prior to exploratory thoracotomy. The epidermal growth factor receptor (EGFR) gene status was assessed by the peptide nucleic acid-locked nucleic acid polymerase chain reaction clamp-based method (9).

Statistical analysis. Survival was defined as the time from surgery until death from any cause. The survival curves of the patients were calculated using the Kaplan-Meier method and statistical evaluation was performed by means of a log-rank test. $\mathrm{P}<0.05$ was considered to indicate a statistically significant difference.

\section{Results}

Patients. A total of 19 patients whose pleural disseminated nodules were identified during surgery were included in this study. The patient characteristics are listed in Table I. The patients comprised 12 men and 7 women with a median age of 65 years (range, 48-80 years). All patients had histologically confirmed adenocarcinoma. The EGFR gene status was evaluated in 10 patients (53\%), of whom 6 were mutant, 5 had exon 19 deletions and 1 had an exon 21 point mutation (L858R). Reclassification was performed according to the TNM revisions (7th edition) and the new stage groupings proposed by IASLC (1). No lymph node metastasis (N0) was diagnosed in 18 patients (95\%) and N1 disease was diagnosed in 1 patient (5\%). Pleural dissemination was detected in all the included patients and was confirmed by pleural biopsy during surgery. Positive pleural lavage cytology was diagnosed in 16 patients (84\%). All patients were diagnosed as stage IV and did not undergo any form of resection.

Systemic chemotherapy. Patients were administered systemic chemotherapy following exploratory thoracotomy. The median time between surgery and systemic chemotherapy initiation was 17 days (range, 7-50 days). The chemotherapy regimens were as follows: 13 patients received carboplatin and paclitaxel, 2 received carboplatin and nab-paclitaxel, 1 received carboplatin and gemcitabine, 1 received carboplatin and paclitaxel plus bevacizumab, 1 received cisplatin and pemetrexed plus axitinib and 1 received cisplatin and gemcitabine. The median number of treatment cycles of first-line platinum-based chemotherapy was 4 (range, 1-6 cycles). The chemotherapy response was evaluated according to the Response Evaluation Criteria in Solid Tumors (RECIST) 1.1 (10). The overall response rate (ORR) was $21 \%$ (95\% CI: 8.5-43), stable disease (SD) was observed in $69 \%$ of the patients, progressive disease (PD) in $5 \%$ and the remaining $5 \%$ of patients were not evaluable. There were no treatment-related mortalities.

Survival. The median PFS and OS were 10.4 (95\% CI: 6.3-18.4) and 50.5 months (95\% CI: 32.5-98.0), respectively (Fig. 1), and the 2- and 5-year survival rates were 84 and $37 \%$, respectively. Following first-line platinum-based chemotherapy, disease progression was observed in 18 of the 19 patients. One patient
Table I. Patient characteristics.

\begin{tabular}{|c|c|}
\hline Characteristics & Values \\
\hline Age, years [median (range)] & $65(48-80)$ \\
\hline \multicolumn{2}{|l|}{ Gender } \\
\hline Male & $12(63 \%)$ \\
\hline Female & $7(37 \%)$ \\
\hline \multicolumn{2}{|l|}{ ECOG performance status } \\
\hline 0 & $17(89 \%)$ \\
\hline 1 & $2(11 \%)$ \\
\hline \multicolumn{2}{|l|}{ Histology } \\
\hline Adenocarcinoma & $19(100 \%)$ \\
\hline \multicolumn{2}{|l|}{ EGFR gene status } \\
\hline \multicolumn{2}{|l|}{ Mutant } \\
\hline Exon 19 deletions & $5(27 \%)$ \\
\hline Exon 21 L858R & $1(5 \%)$ \\
\hline Wild-type & $4(21 \%)$ \\
\hline Unknown & $9(47 \%)$ \\
\hline \multicolumn{2}{|l|}{ Smoking history } \\
\hline Yes & $11(58 \%)$ \\
\hline No & $8(42 \%)$ \\
\hline \multicolumn{2}{|l|}{ Clinical $\mathrm{T}$ factor } \\
\hline $\mathrm{T} 1 \mathrm{a}$ & $1(5 \%)$ \\
\hline $\mathrm{T} 1 \mathrm{~b}$ & $7(37 \%)$ \\
\hline $\mathrm{T} 2 \mathrm{a}$ & $8(42 \%)$ \\
\hline $\mathrm{T} 3$ & $3(16 \%)$ \\
\hline \multicolumn{2}{|l|}{ Clinical $\mathrm{N}$ factor } \\
\hline No & $18(95 \%)$ \\
\hline $\mathrm{N} 1$ & $1(5 \%)$ \\
\hline \multicolumn{2}{|l|}{ Pleural lavage cytology } \\
\hline Positive & $16(84 \%)$ \\
\hline Negative & $1(5 \%)$ \\
\hline Not estimated & $2(11 \%)$ \\
\hline
\end{tabular}

ECOG, Eastern Cooperative Oncology Group; EGFR, epidermal growth factor receptor.

has remained alive without disease progression for $\sim 56$ months; this patient is continuing bevacizumab as maintenance therapy following 6 cycles of carboplatin and paclitaxel plus bevacizumab as first-line chemotherapy. The sites of initial failure are shown in Table II. Of the 18 patients with disease progression, $9(50 \%)$ developed locoregional tumor progression. The remaining 9 patients developed distant tumor progression and the majority had pleural disease progression.

In the EGFR-mutant group, the median PFS was 19.6 months (95\% CI: 6.3-60.2). The median OS was not reached due to the limited number of mortalities. The median follow-up time was 55.3 months (range, 40.2-73.6 months) and the 2- and 5-year survival rates were 100 and $80 \%$, respectively. In the EGFR wild-type or unknown group, the median PFS and OS were 9.8 (95\% CI: 4.2-14.9) and 33.9 months (95\% CI: 17.3-55.1), respectively, and the 2- and 5-year survival 


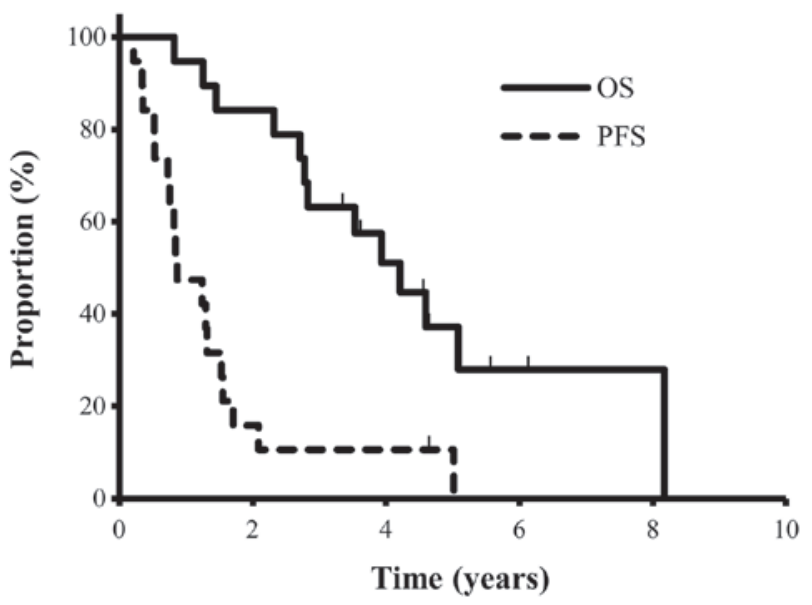

Figure 1. Kaplan-Meier curves of progression-free survival (PFS) and overall survival (OS). The median PFS and OS were 10.4 and 50.5 months, respectively.

rates were 84 and $37 \%$, respectively. The patients positive for EGFR mutations appeared to exhibit a significantly prolonged PFS ( $\mathrm{P}=0.02 ; \mathrm{HR}=0.27 ; 95 \% \mathrm{CI}$ : $0.07-0.81 ; 18$ events) and $\mathrm{OS}$ $(\mathrm{P}=0.02 ; \mathrm{HR}=0.13 ; 95 \% \mathrm{CI}$ : 0.01-0.68; 13 events) compared to the patients with EGFR wild-type or unknown gene status.

Subsequent chemotherapy. The 18 patients who exhibited disease progression following first-line chemotherapy were administered systemic chemotherapy. Second-line chemotherapy regimens are listed in Table III. The 5 patients with EGFR mutations were administered anti-EGFR therapy as second-line chemotherapy. The EGFR gene status was wild-type in 5 patients and unknown in the remaining 8 patients. The second-line chemotherapy regimens were EGFR-tyrosine kinase inhibitors (EGFR-TKIs) in 5, single-agent chemotherapy in 6 and doublet chemotherapy in 2 patients.

\section{Discussion}

In this study, the prognosis for NSCLC patients who received platinum-based chemotherapy following detection of pleural dissemination during surgery was significantly better compared to that of general stage IV NSCLC patients. Previous studies reviewed the $\mathrm{N}$ status and histological characteristics as prognostic indicators for patients with pleural dissemination identified during surgery and suggested that N0 status was a good prognostic indicator, reporting a 5-year survival rate of $24-35 \%$ (11-14). In this study, 18 of the 19 patients (95\%) were classified as N0. Thus, the N factor may be an indicator of prolonged survival. As regards histological characteristics, Mordant et al (11) analyzed 27 NSCLC patients with pleural malignant disease detected during thoracotomy (21 adenocarcinomas and 6 other types of NSCLC) and reported that the histological characteristics were not significantly associated with overall survival $(\mathrm{P}=0.40)$. All patients included in the present study had adenocarcinomas. Therefore, whether histological characteristics had a tendency towards improved survival could not be determined.

Pleural lavage cytology is also considered to be an important prognostic factor. According to the International Pleural Lavage Cytology Collaborators, a positive pleural lavage
Table II. Sites of initial failure.

\begin{tabular}{lc}
\hline Sites & No. $(\%)$ \\
\hline Local & $9(50)$ \\
Distant & $9(50)$ \\
Pleural dissemination & $7(39)$ \\
Lung & $4(22)$ \\
Bone & $2(11)$ \\
\hline
\end{tabular}

Table III. Second-line chemotherapy.

\begin{tabular}{lcc}
\hline & \multicolumn{2}{c}{ EGFR gene status } \\
\cline { 2 - 3 } & $\begin{array}{c}\text { Mutant } \\
(\mathrm{n}=5)\end{array}$ & $\begin{array}{c}\text { Wild-type or } \\
\text { unknown (n=13) }\end{array}$ \\
\hline $\begin{array}{l}\text { Anti-EGFR therapy } \\
\text { Gefitinib }\end{array}$ & 1 & 5 \\
Erlotinib & 1 & \\
Other & 3 & 4 \\
Docetaxel & & 2 \\
Pemetrexed & & 1 \\
Cisplatin + Pemetrexed & & 1 \\
Docetaxel + Aflibercept & & \\
\hline
\end{tabular}

EGFR, epidermal growth factor receptor.

cytology result is an independent predictor of poor survival (15). It was stated that the effect on the survival of patients with positive pleural lavage cytology justified upstaging patients by one $\mathrm{T}$ category. In this study, pleural lavage cytology was performed in 17 patients (89\%) and although only 1 patient was negative and the remaining 16 patients were positive for malignancy, the prognosis was better compared to the M1a designation of the IASLC proposals for stage grouping in the 7th edition of TNM on lung cancer (1).

With regards to the EGFR gene status, the consensus is that EGFR gene mutation is a strong predictor of a better outcome with EGFR-TKIs (16-19). Previous studies on NSCLC patients harboring EGFR mutations reported that the median PFS and OS were 9.6-10.8 and 30.5-35.5 months, respectively, with an ORR of $62.1-73.7 \%$ in patients receiving gefitinib as first-line chemotherapy, whereas the median PFS and OS were 5.4-6.6 and 23.6-38.8 months, respectively, with an ORR of $30.7-32.2 \%$, in patients receiving platinum-based chemotherapy as first-line chemotherapy $(16,17)$. In this study, in the EGFR mutant group, platinum-based chemotherapy was administered rather than EGFR-TKIs and the median PFS was 19.6 months. The median OS was not achieved (the median follow-up time was 55.3 months) and the ORR was 33\%. The EGFR wild-type or gene status-unknown patients in this study also exhibited a longer OS compared to that previously reported (6).

Pleural dissemination indicates the systemic spread of cancer. Systemic chemotherapy is indicated for patients 
with pleural dissemination detected during surgery, which is classified as stage IV with M1a disease. Chemotherapy may suppress tumor progression or micrometastasis and contribute to the improvement of survival rates. As regards local treatment, previous studies supported surgery as an option for NSCLC patients with malignant pleuritis detected during thoracotomy, suggesting that it was beneficial to survival $(11,12,14,20-23)$. Furthermore, Mordant et al (11) reported a long-term survival of $16 \%$ and suggested that identification of clinical T1-2N0 NSCLC with previously undiagnosed pleural malignant metastatic disease may justify surgery as part of a multimodality treatment. In this study, all the patients were administered systemic chemotherapy, but none underwent resection. One patient underwent thoracic radiotherapy [stereotactic radiotherapy (SRT)] following platinum-doublet chemotherapy. That patient, whose EGFR gene status was mutant, was administered carboplatin and paclitaxel as first-line chemotherapy and the best overall response was SD. The tumor size remained unchanged for 8 months after the last administration of chemotherapy and SRT were performed as a curative attempt. The PFS of the patient was 60.2 months, whereas the median PFS was 10.1 months (95\% CI: 6.3-15.7) in the remaining 17 patients. Of the 18 patients, 9 developed initial failure as local progression. A multimodality treatment centered on systemic chemotherapy following local treatment, such as limited resection or radiation, may improve the prognosis of such patients.

In conclusion, platinum-based chemotherapy for NSCLC patients with pleural dissemination detected during surgery demonstrated a favorable prognosis for survival. It is recommended that NSCLC patients with previously undiagnosed pleural dissemination are classified as a special group, for whom systemic chemotherapy followed by local treatment may improve clinical outcomes. Additional multimodality treatment trials are required in this population.

\section{Acknowledgements}

We would like to thank Takaaki Tokito, Kazushige Wakuda, Takuya Oyakawa and Yasushi Hisamatsu, Division of Thoracic Oncology, Shizuoka Cancer Center.

\section{References}

1. Goldstraw P, Crowley J, Chansky K, et al; International Association for the Study of Lung Cancer International Staging Committee; Participating Institutions: The IASLC Lung Cancer Staging Project: proposals for the revision of the TNM stage groupings in the forthcoming (seventh) edition of the TNM Classification of malignant tumours. J Thorac Oncol 2: 706-714, 2007.

2. Postmus PE, Brambilla E, Chansky $\mathrm{K}$, et al; International Association for the Study of Lung Cancer International Staging Committee; Cancer Research and Biostatistics; Observers to the Committee; Participating Institutions: The IASLC Lung Cancer Staging Project: proposals for revision of the $\mathrm{M}$ descriptors in the forthcoming (seventh) edition of the TNM classification of lung cancer. J Thorac Oncol 2: 686-693, 2007.

3. Martini N: Surgical treatment of non-small cell lung cancer by stage. Semin Surg Oncol 6: 248-254, 1990.

4. Ou SH and Zell JA: Validation study of the proposed IASLC staging revisions of the T4 and $\mathrm{M}$ non-small cell lung cancer descriptors using data from 23,583 patients in the California Cancer Registry. J Thorac Oncol 3: 216-227, 2008.
5. Lim E, Ali A, Theodorou P, Nicholson AG, Ladas G and Goldstraw P: Intraoperative pleural lavage cytology is an independent prognostic indicator for staging non-small cell lung cancer. J Thorac Cardiovasc Surg 127: 1113-1118, 2004.

6. Ohe Y, Ohashi Y, Kubota K, et al: Randomized phase III study of cisplatin plus irinotecan versus carboplatin plus paclitaxel, cisplatin plus gemcitabine, and cisplatin plus vinorelbine for advanced non-small-cell lung cancer: Four-Arm Cooperative Study in Japan. Ann Oncol 18: 317-323, 2007.

7. Okamoto I, Yoshioka H, Morita S, et al: Phase III trial comparing oral S-1 plus carboplatin with paclitaxel plus carboplatin in chemotherapy-naive patients with advanced non-small-cell lung cancer: results of a west Japan oncology group study. J Clin Oncol 28: 5240-5246, 2010

8. Schiller JH, Harrington D, Belani CP, et al: Comparison of four chemotherapy regimens for advanced non-small-cell lung cancer. N Engl J Med 346: 92-98, 2002.

9. Nagai Y, Miyazawa H, Huqun, et al: Genetic heterogeneity of the epidermal growth factor receptor in non-small cell lung cancer cell lines revealed by a rapid and sensitive detection system, the peptide nucleic acid-locked nucleic acid PCR clamp. Cancer Res 65: 7276-7282, 2005.

10. Eisenhauer EA, Therasse P, Bogaerts J, et al: New response evaluation criteria in solid tumours: revised RECIST guideline (version 1.1). Eur J Cancer 45: 228-247, 2009.

11. Mordant P, Arame A, Foucault C, Dujon A, Le Pimpec Barthes F and Riquet M: Surgery for metastatic pleural extension of non-small-cell lung cancer. Eur J Cardiothorac Surg 40: 1444-1449, 2011

12. Ichinose Y, Tsuchiya R, Koike T, et al; Japan Clinical Oncology Group: The prognosis of patients with non-small cell lung cancer found to have carcinomatous pleuritis at thoracotomy. Surg Today 30: 1062-1066, 2000.

13. Ohta Y, Shimizu Y, Matsumoto I, Tamura M, Oda M and Watanabe G: Retrospective review of lung cancer patients with pleural dissemination after limited operations combined with parietal pleurectomy. J Surg Oncol 91: 237-242, 2005.

14. Rusch VW, Crowley J, Giroux DJ, et al; International Staging Committee; Cancer Research and Biostatistics; Observers to the Committee; Participating Institutions: The IASLC Lung Cancer Staging Project: proposals for the revision of the $\mathrm{N}$ descriptors in the forthcoming seventh edition of the TNM classification for lung cancer. J Thorac Oncol 2: 603-612, 2007.

15. Lim E, Clough R, Goldstraw P, et al; International Pleural Lavage Cytology Collaborators: Impact of positive pleural lavage cytology on survival in patients having lung resection for non-small-cell lung cancer: an international individual patient data meta-analysis. J Thorac Cardiovasc Surg 139: 1441-1446, 2010.

16. Mitsudomi T, Morita S, Yatabe Y, et al; West Japan Oncology Group: Gefitinib versus cisplatin plus docetaxel in patients with non-small-cell lung cancer harbouring mutations of the epidermal growth factor receptor (WJTOG3405): an open label, randomised phase 3 trial. Lancet Oncol 11: 121-128, 2010.

17. Maemondo M, Inoue A, Kobayashi K, et al; North-East Japan Study Group: Gefitinib or chemotherapy for non-small-cell lung cancer with mutated EGFR. N Engl J Med 362: 2380-2388, 2010.

18. Fukuoka M, Wu YL, Thongprasert S, et al: Biomarker analyses and final overall survival results from a phase III, randomized, open-label, first-line study of gefitinib versus carboplatin/paclitaxel in clinically selected patients with advanced non-small-cell lung cancer in Asia (IPASS). J Clin Oncol 29: 2866-2874, 2011.

19. Mok TS, Wu YL, Thongprasert S, et al: Gefitinib or carboplatin-paclitaxel in pulmonary adenocarcinoma. N Engl J Med 361: 947-957, 2009.

20. Yokoi K, Matsuguma $\mathrm{H}$ and Anraku M: Extrapleural pneumonectomy for lung cancer with carcinomatous pleuritis. J Thorac Cardiovasc Surg 123: 184-185, 2002.

21. Shimizu J, Oda M, Morita K, et al: Comparison of pleuropneumonectomy and limited surgery for lung cancer with pleural dissemination. J Surg Oncol 61: 1-6, 1996.

22. Ichinose $\mathrm{Y}$, Tsuchiya R, Koike T, et al; Japan Oncology Group: Prognosis of resected non-small cell lung cancer patients with carcinomatous pleuritis of minimal disease. Lung Cancer 32: 55-60, 2001.

23. Riquet M, Foucault C and Souilamas F: Lung cancer with pleural dissemination: why not operation? Ann Thorac Surg 74: 1750; author reply 1750,2002 